University of Nebraska - Lincoln

DigitalCommons@University of Nebraska - Lincoln

H. W. Manter Laboratory Library Materials

$9-1914$

Variation in Oxyurias: Its Bearing on the Value of a Nematode

Formula

Stanley B. Fracker

University of Illinois

Follow this and additional works at: https://digitalcommons.unl.edu/manterlibrary

Part of the Parasitology Commons

Fracker, Stanley B., "Variation in Oxyurias: Its Bearing on the Value of a Nematode Formula" (1914). H. W. Manter Laboratory Library Materials. 4.

https://digitalcommons.unl.edu/manterlibrary/4

This Article is brought to you for free and open access by DigitalCommons@University of Nebraska - Lincoln. It has been accepted for inclusion in H. W. Manter Laboratory Library Materials by an authorized administrator of DigitalCommons@University of Nebraska - Lincoln. 


\title{
VARIATION IN OXYURIAS: ITS BEARING ON THE VALUE OF A NEMATODE FORMULA*
}

\author{
Stanley B. Fracker \\ University of Illinois
}

One of the most difficult problems in zoologic science is the classification of round worms. Authors and lecturers, after a carefully outlined and definitely arranged discussion of trematodes and cestodes, are compelled to consider nematodes in a somewhat desultory and inaccurate fashion. Two reasons for this may be given, the greater being the apparent lack of a basis for determining the phylogeny of the major groups, a condition with which we are not at present concerned. The other obstacle is the difficulty of differentiating between species and uncertainty as to the value of different kinds of taxonomic characters. The multitude of synonyms for many of our common insects is a sore point among entomologists, but nemathelminthologists have great difficulty in deciding that any particular name should be relegated to the synonymy.

In the absence of definite structural differences, Dujardin in 1846 found himself compelled to give a few measurements of the length, breadth, tail, etc., of the species which he described. This method was further applied by Eberth in Germany and Bastian in England, followed by Bütschli and others. Finally, in 1890, N. A. Cobb arranged a "nematode formula" which he has applied in all his subsequent work. This formula shows two kinds of measurements: first, the length of the worm in millimeters; second, the percentage of that length which is represented by the distance from the anterior end of the worm to $(a)$ the base of the pharynx, $(b)$ the nerve ring, $(c)$ the cardiac constriction, $(d)$ the vulva, and $(e)$ the anus; and also the width of the body at each of these points. He uses the formulae of different species, both in descriptions and in keys for identification.

Cobb has described something over one hundred species of freeliving round worms of the family Anguillulidae and has always worked out and stated the formula. As there are at present no other scientists making a specialty of this family, it would be unfair to emphasize the fact that, in the quarter century since the description of this formula, it has been used only by its originator. There are,

\footnotetext{
* Contributions from the Zoological Laboratory of the University of Illinois, under the direction of Henry B. Ward, No. 31 .
} 
however, many helminthologists concerned with parasitic Nematoda where the obstacles of classification are equally great. Some of these have seen the possibilities of such a formula, but a real doubt as to its value has prevented them from adopting it. Until the following questions are answered, one must feel that energy and time invested in descriptions of this nature are not well employed:

1. Can the formula be applied at all to the majority of parasitic species?

2. Is the camera-lucida method of measurement sufficiently accurate for such a purpose?

3. Are the relative proportions of the different organs constant within a single species?

Cobb has not discussed these points in his published papers. $\mathrm{He}$ has applied the formula to very few parasitic species and apparently not at all to the difficult ones. He has published no warnings concerning the undoubted distortions caused by the varying tilt of the mirror, or the part of it from which a particular organ is reflected. In no case, so far as I am aware, does he give any indication that he has measured more than one individual of each species. This is especially noticeable in view of the fact that he must have had numerous specimens of some forms and that general attention has been called to this lack in as prominent a place as the Cambridge Natural History.

At the suggestion of Prof. Henry B. Ward of the University of Illinois, the writer recently undertook an investigation of the variation in the proportion of the organs. Incidentally, fragmentary observations on the other two questions are reported.

Cobb's measurements were made on camera-lucida drawings of cleared worms and this procedure has been modified in only one particular. Most of the worms measured by the writer were studied merely in formalin, only about one-fourth having been dehydrated and cleared in carbol xylol. None were mounted in balsam but all were studied under a cover-glass. The greatest care was used to avoid errors due to faulty technic, such as would be caused by accidental differences in the position of the camera-lucida. The effect of transfering the specimens from formalin to the clearing agent was not determined but is probably slight. The first fourteen worms whose measurements are reported in the table were cleared.

The first species of which drawings were made with a view to measurement was the hookworm, Necator americanus Stiles. Unfortunately, this is bent in two planes, the head being hooked at a right angle to the general body curvature. In addition, the males, of which most of the available material consisted, have the anus at the tip of 
the body. The body wall is so opaque that locations of internal structure are difficult to determine, and the writer was unable to discover any method of making the nerve ring visible. For these reasons the conclusion was reached that the formula could not be satisfactorily used on these worms and work on the species was abandoned.

Accurate measurement of larger worms, such as Ascaridae, was out of the question, no apparatus adaptable to this use being available or on the market. These facts partially answer the first two problems involved, it being clear, first, that the Strongylidae, especially the hookworms, do not readily lend themselves to classification by this means; second, that the camera-lucida method of measurement now in vogue is not applicable to worms exceeding $1 \mathrm{~cm}$. in length. Possibly the latter obstacle may still be overcome by the use of special apparatus if the formula proves its worth in other points.

The department of zoology then secured about one hundred specimens of Oxyurias vermicularis Linn., the pinworm of man. These were all from one host, living in a rural locality in Kentucky, and were all voided at the same time. It soon became clear that, among the parasitic genera, Oxyurias is ideal for such work. The specimens were preserved in formalin, and at first the vulva could not be located with certainty, but clearing in carbolxylol corrected that difficulty. As a consequence, the writer was able to make a rigorous test of practically all of Cobb's characters except the position of the nerve ring, which could not be determined, owing to the preservative. It may be noted in passing that the nerve ring is often difficult to locate, one of Cobb's largest papers (1893) omitting that character in the formulae of onethird of the species. Cobb gives (1890a) the formula for a young individual of $O$. vermicularis, but its immature condition invalidates any possible comparison with the results given here.

The purpose of this work was not to examine critically the particular points located by Cobb, but to ascertain the extent to which the proportions of the worm were constant, and the parts which undergo the greatest variation. The results should be of interest, both to parasitologists and to systematists, regardless of their relation to this particular formula or group.

The unit of measurement used was 1 per cent. of the length of the individual. Measurements were made on this basis from the anterior end (1) to the caudal margin of the cephalic swelling; (2) to the beginning of the esophageal bulb; (3) to the cardiac constriction; (4) to the vulva; (5) to the anus; (6) to the anterior and posterior limits of the internal reproductive organs. The width at each of these points was also determined. Finally, the total length of the worm was calculated. Fifty-two individuals were measured, but 
in most of them one character or another was so indefinite that the writer did not feel justified in recording what appeared to be its location. This was especially true of the vulva, invisible in uncleared material.

The following table gives the measurements of each worm studied. In the first column is the arbitrary number of the specimen. The second gives the length of the worm in millimeters. The figures in all the other columns indicate the percentage of the length of the worm from the cephalic end to that particular point, the columns being numbered as in the last paragraph. Column 6, however, shows only the interval occupied by the reproductive organs. " $L$ " indicates length and "W" width. Finally, for each of these characters, there is recorded $(a)$ the average, $(b)$ the number of specimens on which the character was determined, $(c)$ the "standard of variation," $(d)$ the maximum and $(e)$ the minimum measurement found, and $(r)$ the range. The average is the sum of all the measurements divided by $(b)$. The standard of variation was calculated by the well-known formula, $\left(\sigma=\sqrt{\frac{2(\mathrm{x}-\mathrm{f})}{\mathrm{n}}}\right), x$ being the deviation of a class from the average, and $f$, the number in the class. The range is merely the maximum, $(d)$, minus the minimum, $(e)$.

Attention should be called to the fact that results $(a)$ and $(c)$ were calculated from measurements to the second decimal place. In order to limit space it was thought desirable to omit the second place in the printed record. This will explain any slight discrepancies which might confuse, should these results be checked over. The lack of value of the second or even the first decimal place is discussed in a later paragraph.

The average length of the body of this species is $7.39 \mathrm{~mm}$. The range is about one-fourth of the maximum length. As the curve is normal, the total range in the species is probably not much greater than this.

1. The external cephalic swelling is peculiar to the species studied and is a secondary development of no great definiteness or importance. The curve of the variation in its length is an irregular one and far from the normal type. It will be noted that the range is over twofifths of the maximum, and that the standard of variation is 0.397 per cent., or about one-ninth of the maximum. In view of the nature of this feature, considerable variation was to be expected.

2. The esophageal bulb marks a distinct division of the alimentary canal and is bounded by two definite constrictions. The esophagus, which leads from the mouth to this bulb, is straight or slightly bent, in no case being sufficiently curved to draw the bulb out of its position. Variation is from 8.3 per cent. to 12.1 per cent., a range of 3.8 per cent. 


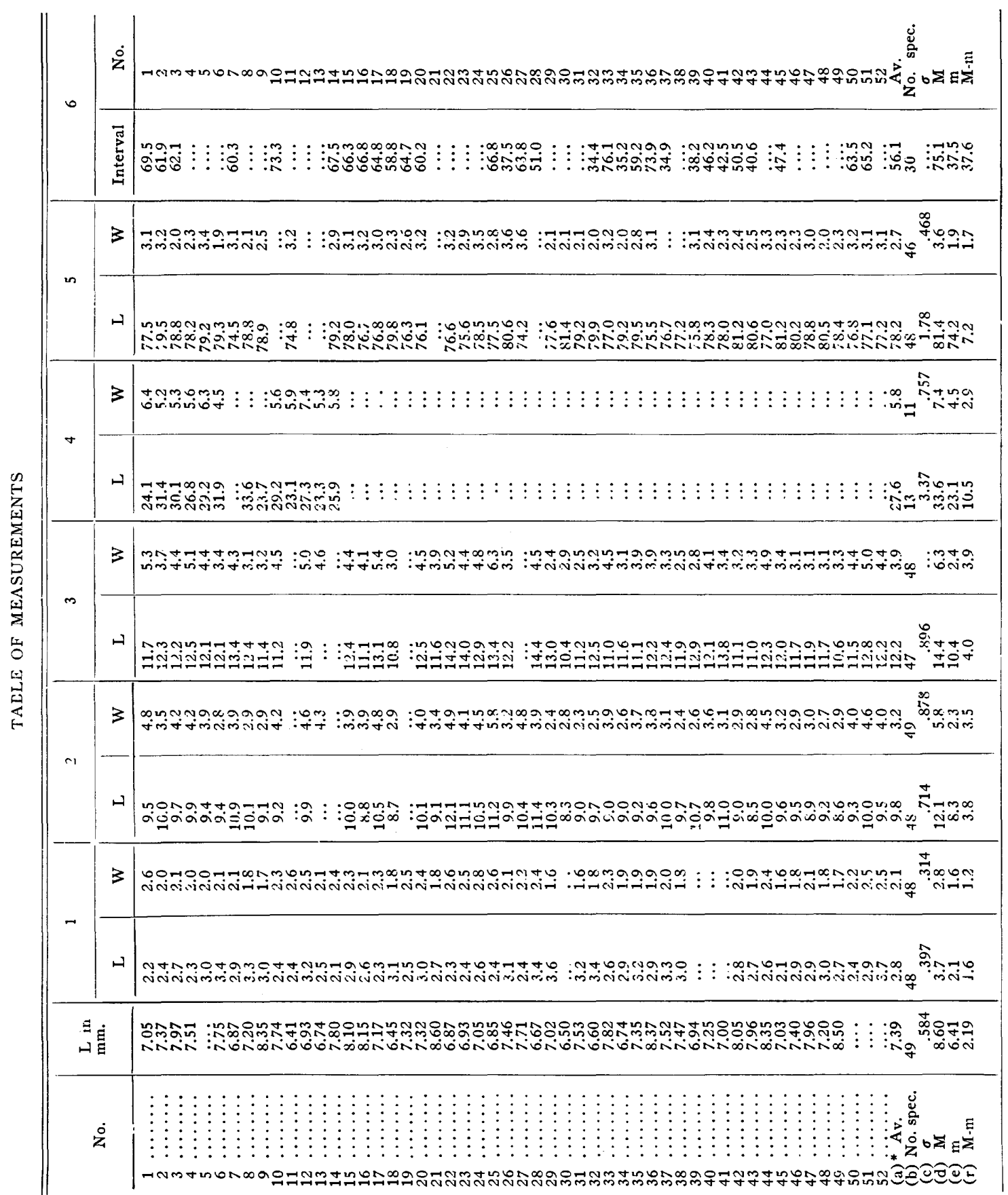


The magnitude of the range and of the standard of variation is striking.

3. The cardiac constriction is the caudal limit of the esophageal bulb, which occupies from 2 to 3 per cent. of the length of the worm. The distance of this constriction from the mouth varies from 10.4 to 14.4 per cent., and the range, 4 per cent., is about two-sevenths of the maximum. This range overlaps about one-sixth of all the species Cobb has described in the papers at hand.

4. Only thirteen individuals were studied in which the vulva could be located, it being invisible in the opaque formalin material. In the cleared specimens, the range in its position was about one-third of the maximum distance from the mouth. The standard of variation, 3.37 per cent., is over four times that of any of the first three structures.

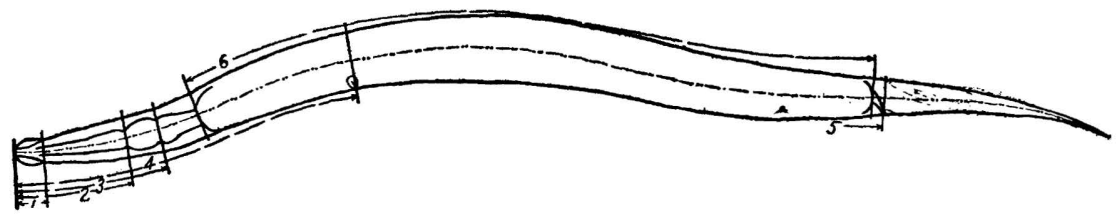

Fig. 1.-Oxyurias vermicularis Linn. Specimen No. 2; lateral aspect of cleared worm. 1-6, the structures and distances measured in this paper; for explanation see text, and table opposite.

5. The anus is usually located in the caudal fourth of the body, its position varying from 74.2 to 81.4 per cent., a range of 7.2 per cent. The standard of variation is 1.78 per cent., or midway between those of the last two structures. Some reliance, therefore, can be placed on measurements of the location of the anus.

6. In the use of the formula, the interval occupied by the reproductive organs is given in an approximate and general way. Cobb usually uses a multiple of 10 per cent. to express this distance. Even this approximation, however, appears to be of no value in Oxyurias. In some cases these organs reach from a point near the mouth (5.7 per cent.) to a point behind the anus ( 86.9 per cent.), often obscuring the latter's position. In other specimens they have shrunken to a small size or are undeveloped. The interval occupied varies from 37.5 to 75.1 per cent., a range of 37.6 per cent. Such a condition makes the recording of this interval in the specimens at hand when a species is described a waste of labor.

While measurements of the lengths of different structures vary independently of each other, this is not true of the widths at different points. For this reason separate discussions of the latter are not necessary. In almost all cases the range in widths is approximately equal to, or greater than, the width of the most slender worm studied. So few specimens were measured at the vulva that the range there is 
not as great as it should be, neither the slimmest nor plumpest worms having been measured at this point. Taking the width at the cardiac constriction as typical, we find a variation of from 2.4 to 6.3 per cent. The latter worm was particularly contracted, however, the normal range being from 2.4 to 5.4 per cent., as shown by the curve of variation.

If structures were correlated with each other, considerable reliance could be placed on the body proportions in spite of the individual variation. It was hoped that a study of correlation would yield results which would assist in the interpretation of the relation between an unnamed specimen and a given formula. The attempt to find such assistance, however, must be considered a failure.

Correlation diagrams were made to show the relation of the width of the body to the length of the esophagus, the length of the alimentary canal to the length of the esophagus, the relation of the position of the vulva to that of the anus and to that of the cardiac constriction, etc. In no case was there the least indication of correlation, except between the length of the esophagus and the position of the cardiac constriction. As the esophageal bulb which separates these is small and rather constant in size, this fact can hardly be called a true correlation.

Much of the importance of a study of variation in its relation to classification depends on the differences between the various species with the group concerned. Thus, if all Nematoda had an esophagus about one-eighth the length of the body, had the vulva placed within the cephalic third, and the anus near the beginning of the caudal fourth of the total length, a variation no greater than occurs in Oxyurias would make the measurement method valueless in identification. The formulae of about one hundred species described by N. A. Cobb were, therefore, examined in order to determine the variation within the class. In some cases curves were plotted.

This examination showed an ideal condition for such a scheme. A curve including the formulae of the described species is similar to a long, low mountain range. All possible changes in the proportions seem to have been observed. As a result, the range of each of the characters given above covers only one-fifth to one-tenth of the described species. In some cases it is less than that. For example, the vulva, in the eighty-five species whose descriptions happen to be before me at the moment, varies from 20 to about 80 per cent. in position. Of these, only five species are between the maximum and minimum found in the specimens of Oxyurias reported in this paper. Forty of them, however, or nearly half, are between 45 and 55 per cent., a range less than that in this species. The fact, therefore, that the range appears unimportant in this case seems to be an accident of the species chosen. 
In tables for identification, Cobb has used such characters as "Tail 15 per cent.," as opposed to "Tail 20 per cent."; or "Body slender (little more than 2.6 per cent.)" in opposition to "Body not so slender (3 per cent. or over)." In these and many other places the difference specified is less than the range in this one species.

In general, the variations recorded here may be due to two causes: (a) varying state of contraction owing to chemical technic, conditions of killing, etc., and $(b)$ ordinary fluctuating variations. General body contraction would not affect the positions of the organs and can scarcely account for differences in length percentages. On the other hand it would have an important effect on the width. Thus the length percentages, depending largely on fluctuating individual variations, are not correlated with the widths, most of which are determined by the state of contraction. The impossibility of securing uniform contraction makes it necessary to consider width measurements unreliable.

In the practice of identification of specimens two advantages may be claimed for a formula. In the first place it is an abbreviated record of what would be a long description. This advantage cannot be gainsaid and is the principal source of the strength of the "nematode formula." In the second place a comparison of the formula of a specimen at hand with those of a series of descriptions might aid in identification. This is the advantage which has been emphasized too much. The following are the formulae of a few of the specimens of Oxyurias vermicularis:

\begin{tabular}{|c|c|c|c|c|c|c|}
\hline \multirow{2}{*}{ No. 1.} & 2.2 & 9.5 & 11.7 & $24.1^{711}$ & 77.5 & \multirow{2}{*}{$7.05 \mathrm{~mm}$. } \\
\hline & 2.6 & 4.8 & 5.3 & 6.4 & 3.1 & \\
\hline \multirow{2}{*}{ No. 2.} & 2.4 & 10.0 & 12.3 & $31.4^{62}$ & 79.5 & \multirow{2}{*}{$7.37 \mathrm{~mm}$. } \\
\hline & 2.0 & 3.5 & 3.7 & 5.2 & 3.2 & \\
\hline \multirow{2}{*}{ No. 7.} & 2.9 & 10.9 & 13.4 & $?^{601}$ & 74.5 & \multirow{2}{*}{$6.87 \mathrm{~mm}$. } \\
\hline & 2.1 & 3.9 & 4.3 & $?$ & 3.1 & \\
\hline \multirow{2}{*}{ No. 26.} & 3.1 & 9.9 & 12.2 & $?^{37}$ & 80.6 & \multirow{2}{*}{$7.46 \mathrm{~mm}$. } \\
\hline & 2.1 & 3.2 & 3.5 & $?$ & 3.6 & \\
\hline \multirow{2}{*}{ No. 42.} & 2.8 & 9.0 & 11.1 & $?^{3010}$ & 81.2 & \multirow{2}{*}{$8.05 \mathrm{~mm}$} \\
\hline & 2.0 & 2.9 & 3.2 & $?$ & 2.4 & \\
\hline
\end{tabular}

These figures do not refer to the exact points used by Cobb, but the principle is the same. If the species had been described from No. 7 and that formula given as typical, it is doubtful whether it would aid in naming No. 26 or any of the others. 


\section{CONCLUSIONS}

The proportionate size of the organs in Nematoda is an important factor in their identification and should be stated in any description of a new species.

The locations of the cephalic parts of the alimentary canal tend to vary from 1 to 4 per cent., about one-third of the maximum, in $O x y$ urias vermicularis.

The location of the vulva probably varies at least 15 per cent. in a long series of individuals.

The location of the anus varies over 7 per cent., or about one-third of the length of the tail.

Variations in width are so great that some individuals are over twice as wide as others.

The length of the body of some individuals is one-third greater than that of others.

The use of the formula is likely to yield more confusion than assistance. It is impossible to indicate the observed range, and without that the numbers are meaningless. Carrying the measurement to one-tenth of 1 per cent., gives an appearance of accuracy which does not exist. The formula is likely to result in the multiplication of so-called species without a proper basis for their separation.

A species should not be described as new on account of a deviation from the proportions of known species unless that deviation is great and fundamental. The space occupied by the reproductive organs should not be considered, and little dependence should be placed on the width of the body. From four to ten individuals should always be studied and the observed range recorded. In this way the varying proportions of the different species can be used in the identification of collected specimens. An individual should never be identified, however, on the basis of the formula alone or of the proportions alone.

REFERENCES CITED

Cobb, N. A. 1890. A Nematode Fermula. Agr. Gaz., N. S. W., 11:131-135. 1890a. Oxyuris Larvae Hatched in the Human Stomach under Normal Conditions. Proc. Linn. Soc., N. S. W., 5: $168-185$.

1890b. Arabian Nematodes. Proc. Linn. Soc., N. S. W., 5: $449-468$.

1893. Nematodes, Mostly Australian and Fijian. Dept. Agr., N. S. W., Misc. Publ. 13, 59 pp.

1902. The Nematode Fermula. Agr. Gaz., N. S. W., 13:10231030.

1913. New Nematode Genera Found Inhabiting Fresh Water and Non-Brackish Soils. Jour. Wash. Ac. Sci., $3: 432-$ 444. 